\title{
Educação ambiental no Geopark Araripe: contribuição para o ensino de geografia
}

\author{
Environmental education at Geopark Araripe: contribution to the teaching of geography \\ Educación ambiental en el Geopark Araripe: contribución a la enseñanza de la geografia
}

\author{
Bruna Almeida de Oliveira \\ ORCID: https://orcid.org/0000-0003-3937-8038 \\ Universidade Regional do Cariri, Brasil \\ E-mail: brunalmeidaprof@gmail.com \\ João César Abreu de Oliveira \\ ORCID: https://orcid.org/0000-0001-5398-8196 \\ Universidade Regional do Cariri, Brasil \\ E-mail: njcesar@bol.com.br \\ Selton David Cavalcante Sobral \\ ORCID: https://orcid.org/0000-0002-9050-6157 \\ Universidade Federal do Cariri, Brasil \\ E-mail: sobralsdc@gmail.com \\ Tânia Kelly Mendes Feitosa \\ ORCID: https://orcid.org/0000-0002-3086-5342 \\ Universidade Regional do Cariri, Brasil \\ E-mail: professorakellymendes047@gmail.com \\ Elias Laurindo de Oliveira \\ ORCID: https://orcid.org/0000-0002-2456-8296 \\ Universidade Regional do Cariri, Brasil \\ E-mail: eliasescarpa@gmail.com \\ Elizângela Beneval Bento \\ ORCID: https://orcid.org/0000-0002-7516-9711 \\ Universidade Regional do Cariri, Brasil \\ E-mail: elizangelaeliz@yahoo.com.br \\ Dieferson Leandro de Souza \\ ORCID: https://orcid.org/0000-0002-8887-4620 \\ Universidade Regional do Cariri, Brasil \\ E-mail: diefersonleandro@gmail.com \\ Bruno Melo de Alcântara \\ ORCID: https://orcid.org/0000-0002-1934-4298 \\ Universidade Regional do Cariri, Brasil \\ E-mail: brunomelo870@gmail.com \\ Cicera Emanuela Arrais Alexandre \\ ORCID: https://orcid.org/0000-0002-1996-2424 \\ Universidade Regional do Cariri, Brasil \\ E-mail: manu.sementes@gmail.com \\ Priscilla Augusta de Sousa Fernandes \\ ORCID: https://orcid.org/0000-0001-7357-1013 \\ Universidade Regional do Cariri, Brasil \\ E-mail: prisciasf@gmail.com \\ Thiago Felix de Lima \\ ORCID: https://orcid.org/0000-0001-8577-4635 \\ Universidade Federal do Cariri, Brasil \\ E-mail: lima.thiago@aluno.ufca.edu.br \\ Maria Aparecida Barbosa Ferreira Gonçalo \\ ORCID: https://orcid.org/0000-0003-4974-2606 \\ Universidade Regional do Cariri, Brasil \\ E-mail: cida_barba@hotmail.com \\ Maraiza Gregorio de Oliveira \\ ORCID: https://orcid.org/0000-0002-2855-641X \\ Universidade Regional do Cariri, Brasil
}

\section{Resumo}

A Educação Ambiental no GeoPark Araripe se baseia na tentativa de fortalecer visões de integração e interdisciplinaridade que estimulem uma reflexão sistemática na diversidade socioambiental dentro do seu território. Nesse sentido, o primeiro passo para realização dessas ações é identificar as representações sobre elas envolvidas no processo educativo, participando na promoção do exercício da cidadania e da melhoria da qualidade de vida, a Educação Ambiental no GeoPark Araripe possui uma grande diversidade de experiências, reflexões e compromissos, 
que têm em comum a transformação a sensibilização da sociedade através da "educação", a expansão dos ideais de Educação Ambiental é um desafio , sem dúvida metas que só serão atingidas a médio e longo prazos. O objetivo principal desta pesquisa é perceber a contribuição valorosa que o GeoPark Araripe fornece para o ensino de geografia por meio da Educação Ambiental, se caracteriza como uma pesquisa qualitativa, pois se trata de uma pesquisa que visa conhecer e interpretar aspectos e características da temática e do grupo estudado.

Palavras-chave: Interdisciplinaridade; Educação; Socioambiental.

\begin{abstract}
Environmental Education at GeoPark Araripe is based on an attempt to strengthen visions of integration and interdisciplinarity that encourage a systematic reflection on socio-environmental diversity within its territory. In this sense, the first step to carry out these actions is to identify the representations about them involved in the educational process, participating in promoting the exercise of citizenship and improving the quality of life. Environmental Education at GeoPark Araripe has a great diversity of experiences, reflections and commitments, which have in common the transformation and awareness of society through "education", the expansion of the ideals of Environmental Education is a challenge, without a doubt goals that will only be achieved in the medium and long term. The main objective of this research is to realize the valuable contribution that GeoPark Araripe provides for the teaching of geography through Environmental Education, it is characterized as a qualitative research, as it is a research that aims to know and interpret aspects and characteristics of the theme and of the studied group.
\end{abstract}

Keywords: Interdisciplinarity; Education; Socio-environmental.

\title{
Resumen
}

La Educación Ambiental en GeoPark Araripe se basa en un intento de fortalecer visiones de integración e interdisciplinariedad que propicien una reflexión sistemática sobre la diversidad socioambiental dentro de su territorio. En este sentido, el primer paso para llevar a cabo estas acciones es identificar las representaciones sobre ellos involucrados en el proceso educativo, participando en promover el ejercicio de la ciudadanía y mejorar la calidad de vida.La educación ambiental en GeoPark Araripe tiene una gran diversidad de experiencias, reflexiones y compromisos, que tienen en común la transformación y concienciación de la sociedad a través de la "educación", la expansión de los ideales de la Educación Ambiental es un desafío, sin duda metas que solo se lograrán en el mediano y largo plazo. El objetivo principal de esta investigación es dar cuenta del valioso aporte que GeoPark Araripe brinda para la enseñanza de la geografía a través de la Educación Ambiental, se caracteriza por ser una investigación cualitativa, ya que es una investigación que tiene como objetivo conocer e interpretar aspectos y características de la temática. y del grupo estudiado.

Palabras clave: Interdisciplinariedad; Educación; Socioambiental.

\section{Introdução}

A Educação Ambiental (EA) permite encontrar caminhos para o equilíbrio ambiental, econômico e social, configurando-se como uma ferramenta de sensibilização e mobilização, visando assim um espaço menos degradado, relacionando sociedade e natureza, a educação ambiental abre um estimulante e variado espaço para repensar as práticas sociais, permitindo a base adequada de compreensão do ambiente, da interdependência de problemas e soluções e da responsabilidade de construir uma sociedade mais justa ambientalmente (Galvão, 2007). A educação ambiental envolve ações e práticas educativas voltadas à sensibilização da coletividade sobre as questões ambientais e à sua organização e participação na defesa da qualidade do meio ambiente (Klein et al., 2011). Conforme a lei federal nº 9.795/1999 é dever do poder público: "promover a educação ambiental em todos os níveis de ensino e a conscientização pública para a preservação do meio ambiente".

O GeoPark Araripe ultimamente tem assumido um caráter efetivo frente à busca de conhecimentos sobre a temática ambiental, possivelmente devido ao aumento das questões ambientais, por estar em contato com as comunidades de onde estão inseridos os geossitios por estar sempre em meio às ações que envolva a temática (Governo do Estado do Ceará, 2012). Sempre em contato com as instituições de ensino por meio de suas ações, tendo em vista que o GeoPark não tem função fiscalizatória, então como preservar o patrimônio geológico e a biodiversidade local ? Como levar temas relacionados à questão da preservação para dentro da sala de aula e que a mesma seja proveitosa para além das paredes da escola? O objetivo principal desta pesquisa é perceber a contribuição valorosa que o GeoPark Araripe fornece para o ensino de geografia por meio da Educação Ambiental. 
Torna-se imprescindível a adoção de ações educativas voltadas para a conscientização coletiva e à participação na defesa do ambiente, na qual podem atuar distintos atores sociais e políticos, como o poder público na promoção e difusão de campanhas educativas relativas à geodiversidade, à participação das empresas públicas e privadas, meios de comunicação, ONGs (Organização Não Governamentais), escolas e sociedade na formulação, execução e desenvolvimento de programas e atividades vinculadas com a Educação Ambiental (Brasil, 1999), associadas à introdução da discussão sobre geodiversidade entre as temáticas físico-naturais da Geografia Escolar (Albuquerque, 2019) permitindo assim, a articulação entre o objeto a ser conservado/divulgado à ferramenta educacional.

Dessa maneira, as pessoas precisam compreender o papel delas na sociedade e seus atos perante o meio ambiente. Evidencia-se, então, a imposição de um novo paradigma de sustentabilidade, limitação dos recursos não renováveis e superação da ideia psíquica que relaciona o consumo à felicidade (Friede et al., 2019).

A Educação Ambiental enxerga a crise ambiental existente como uma questão advinda das relações sociais, entre o ser humano e o meio ambiente efaz uma crítica ao sistema capitalista vigente, buscando superar esta hegemonia. Essa abordagem se destaca pelo vínculo dos espaços formais e não-formais de ensino; pela proximidade entre a instituição e à comunidade atendida; pela idealização integral das atividades curriculares e extracurriculares e pelo vínculo das ações cognitivas com as transformações das práticas socais (Loureiro, 2004; 2007; Santos \& Toschi, 2015; Lopes \& Abílio, 2021).

Através de ações atividades realizadas voltadas para educação no geral, as oficinas, palestras, atividades lúdicas como as trilhas de cunho educativo pedagógico, então as ações são sempre realizadas em prol da conscientização das pessoas visando ampliar as oportunidades educacionais, discutir os conhecimentos, debater a geografia dentro da temática. Educação Ambiental parte do princípio de educação, ou seja, essa adjetivação do termo "educação ambiental" tem, porém é educação como um todo, pois sendo assim é uma educação que engloba, seja numa região em qualquer lugar do mundo, ela venha a ter um desenvolvimento um crescimento uma sustentabilidade, a temática é ampla, falar em educação ambiental é falar em ética. Segundo Reis et al. (2012), para implementar de forma eficaz programas relacionados à educação ambiental não-formal é imprescindível primar pela oportunidade de participação que deve ser dada a todos os envolvidos, permitindo questionamentos e soluções para objetivos traçados.

Os Centros de Educação Ambiental (CEA) foram oficialmente criados no Brasil pelo Ministério da Educação e Cultura em 1993, a partir da realização do I Encontro Nacional de Centros de Educação Ambiental, realizado no ano de 1992, em Foz do Iguaçu/PR. Com a realização do RIO-92, houve uma influência na questão ambiental no Brasil proporcionando a formalização dos CEA's como recursos de complementação e mudança na formação integral do cidadão (Silva \& Sorrentino, 2012).

O GeoPark Araripe possui três centros de Educação Ambiental, Crato/CE, Missão Velha/CE e Nova Olinda/CE, nesses centros são desenvolvidas atividades voltadas para o lúdico sempre focando na questão ambiental e inclusão. A partir desse estudo, verifica-se que o CEA contribui bastante para o processo educacional, e que o trabalho desenvolvido neste espaço vem sendo cada vez mais aceito e procurado pela comunidade dos geossitios e em geral na sociedade.

\section{Metodologia}

Esse trabalho caracteriza-se por uma pesquisa qualitativa, pois se trata de uma pesquisa que visa conhecer e interpretar aspectos e características da temática e do grupo estudado. A pesquisa qualitativa, segundo Ludke e André (2013, p.18), é o que se desenvolve numa situação natural; é rico em dados descritivos, tem um plano aberto e flexível focalizando a realidade de forma contextualizada. A análise qualitativa trabalha todo material obtido durante a pesquisa, ou seja, as observações, as análises de documentos e as demais informações disponíveis (Ludke \& André, 2013).

Foi utilizada a observação sistemática, a qual tem uma estruturação, planejamento e um controle já elaborado, levando 
o pesquisador a uma facilitação no desenvolvimento dos trabalhos, e consecutivamente melhorará a aquisição dos conhecimentos do mesmo no decorrer do estudo (Macedo, 2012). As observações efetuadas durante o estudo foram registradas por meio de anotações de campo, registros fotográficos, o qual é de fundamental importância, pois foi um instrumento de auxílio no aperfeiçoamento da capacidade de observação. O mesmo fez com que em um único lugar pudesse reunir várias informações, que foram analisadas posteriormente. Ainda foram analisados programas e relatórios técnicos do GeoPark Araripe, para levantamento de dados sobre atividades realizadas no CIEA, material estes que contribuíram significativamente para elaboração deste trabalho.

Foram utilizadas leitura de artigos e textos que tratam especificamente da temática trabalhada na pesquisa, livros sobre educação ambiental e livro sobre GeoPark Araripe além de toda vivência, do qual se faz recorte espacial, anotações feitas em Fóruns de Turismo, conhecimento adquirido em: Oficinas, trilhas ecológicas, participação em eventos sobre Educação Ambiental. Trabalho realizado na área do turismo pedagógico, assim como trabalho de campo, analisando tanto os aspectos geoambientais como também uma observação social do ambiente estudado e matérias que dizem respeito às ações desenvolvidas pelo GeoPark Araripe em seu território, realização e vivência das ações junto ao setor e os membros do GeoPark Araripe em quanto bolsista no período de 1 ano e 6 meses, vivência no CIEA do Crato/CE (Centro de Interpretação de Educação Ambiental) acompanhamento das atividades voltadas para Educação Ambiental junto as escolas que abrangem o território do GeoPark Araripe, observação e participação nas atividades, desenvolvimento de trabalho voluntario no período de 6 meses no Centro de Interpretação de Educação Ambiental (CIEA). Pode se dizer que a educação ambiental é um tema amplo, pode ser trabalhada no cotidiano saindo dos trabalhos acadêmicos sendo colocada em prática, com uma aplicabilidade social.

\section{Resultados e Discussão}

O Público beneficiado pelas ações educativas do GeoPark Araripe são escolas públicas e privadas, existe metas que só serão alcançadas a médio e longo prazos, o GeoPark Araripe busca trabalhar na realização de ações urgentes e nos projetos que existe tempo diferenciado para começar a mostrar resultados.

O Centro de Interpretação e Educação Ambiental - CIEA do GeoPark Araripe foi criado em junho de 2010, tendo a identidade histórica, ambiental e cultural do povo Caririense como base. O mesmo está localizado no Parque de Exposição Pedro Felício Cavalcante, no município de Crato-CE. Em dezembro de 2013, foi inaugurada uma extensão do CIEA em Missão Velha, localizado no apoio rodoviário (Macedo, 2015). No CIEA é realizado o acolhimento de visitantes, turistas, alunos de escolas do ensino infantil, fundamental, ensino médio e superior; realização de cursos, projetos, oficinas e palestras, com objetivo de disseminar o conhecimento sobre o G.A, ações educacionais de preservação e conservação bem como preparação de agentes multiplicadores de E.A (Educação Ambiental).

As visitas ao CIEA são realizadas por agendamentos prévios ou por visitas espontâneas. Os agendamentos prévios são feitos com pelo menos quinze dias de antecedência por meio de ofício, geralmente são feitos por escolas e universidades e outras instituições de cunho educacional, pois esse meio possibilitará que os interessados tenham acesso à realização de oficinas as quais devem ser escolhidas com antecedência para serem providenciados os materiais necessários. As visitas espontâneas acontecem principalmente por vinda de turistas e visitantes que estão passando pela região.

O acolhimento no CIEA começa com uma exposição sobre "Geoparques "e o GeoPark Araripe e em seguida é feita uma apresentação dos geossítios, mostra de vídeo, conversa sobre as oficinas, distribuição de material explicativo e pedagógico bem como realização de oficina. No CIEA são desenvolvidos projetos para sustentabilidade ambiental e de divulgação dos trabalhos do G.A, proporcionando um processo educativo direto na população atendida.

O Projeto Oficinas Pedagógicas busca despertar a importância do G.A na construção de uma Educação Ambiental que possibilite a mudança de hábitos, relacionando pequenas atitudes do dia-a-dia com a sustentabilidade. São desenvolvidas com 
escolas de todos os níveis de ensino, sejam elas públicas ou particulares, instituições de nível superior e a comunidade em geral. As principais oficinas realizadas no CIEA são: Oficina de Réplicas de Fósseis em Gesso.

Por se fazer bastante presente no território do GeoPark Araripe uma multiplicidade de fósseis que são restos ou vestígios preservados de animais, plantas ou outros seres vivos em rochas, como moldes do corpo ou partes deste, rastros e pegadas que datam de milhares de anos, e diante do fato de estes serem alvo do tráfico e exploração ilegal, são realizadas as oficinas de réplica que tem por objetivo abordar a importância da preservação e manutenção desse patrimônio presente nas formações geológicas da Bacia Sedimentar do Araripe.

Esta oficina é uma atividade reconhecida como importante para a divulgação dos fósseis existentes na região bem como é entendida enquanto forma de educar para não ocorrer à venda e sim a entrega destes fósseis encontrados no Museu de Paleontologia da URCA, a oficina de argila, bastante procurada principalmente nas ações do GeoPark Araripe.

Oficina de Brinquedos (Figura 1) com reutilização de materiais recicláveis, essa oficina propõe a reutilização de materiais recicláveis através do fazer artístico. A sensibilização das crianças acerca dos resíduos sólidos jogados no território do GeoPark Araripe é bastante evidenciada tanto nas orientações que são proferidas quanto nas atividades de construção de artefatos e brinquedos. As garrafas-pet, material bastante presente no lixo produzido pela população, servem de matéria-prima para a imaginação e inventividade.

Figura 1 - Bonecos confeccionados para apresentação teatral.

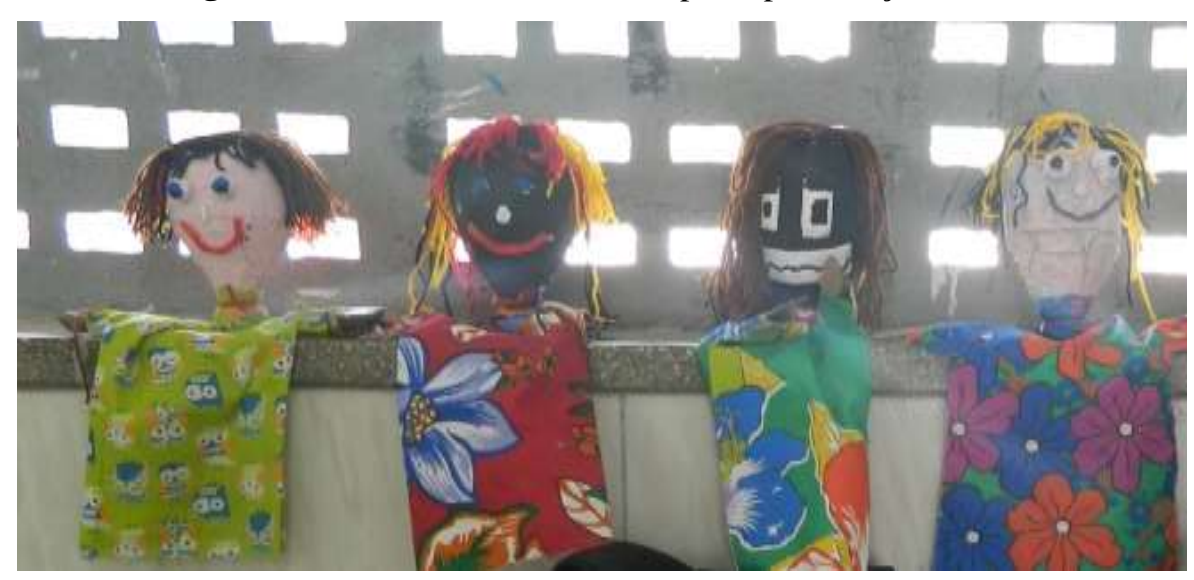

Foto: Acervo GeoPark Araripe (2016).

Essas oficinas apresentadas possibilitam o conhecimento a partir de atividades lúdicas, facilitando assim, o acesso a práticas educacionais que possibilitam uma formação cidadã pautadas nas questões ambientais e sociais. No projeto Colônia de Férias do GeoPark Araripe são trabalhadas atividades de integração de crianças com a natureza de forma lúdica e educativa, através de oficinas, dinâmicas, gincanas, brincadeiras, jogos e trilhas que contribuem para a formação de agentes multiplicadores de educação ambiental e proporcionem conhecimentos sobre o G.A, a preservação e conservação ambiental. Desde 2016 já foram realizadas 27 (vinte sete) colônias de férias nos seis municípios que compreendem o território do G.A, atendendo a um público estimado em 3.500 participantes. Do ponto de vista teórico-metodológico, a oficina funciona como uma estratégia facilitadora da troca dialógica e da construção de sentidos, cujos procedimentos metodológicos, à primeira vista, parecem articular grupos focais (Ressel et al., 2008). Segundo Catalão (2011, p.74), ao desenvolver pesquisas na área de educação ambiental "toda aprendizagem do ser vivo resulta em uma transformação individual, uma co-evolução e uma mudança ambiental". Sair do ambiente escolar, por si só gera um efeito positivo sobre o interesse dos alunos pelo conteúdo (Farina \& Guadagnin, 2007, p. 111).

Ressaltando, que desde a implantação, o Centro de Interpretação e Educação Ambiental em 2010, já recebeu, 
aproximadamente, 29.000 visitantes, e no mesmo período foram realizadas 497 oficinas já citadas, atendendo a um público estimado em 14.910 participantes. Como foram apresentados anteriormente, todos os projetos tornam o CIEA um grande meio de desenvolvimento educacional, através da interdisciplinaridade de conteúdo existente em um espaço disponível para toda comunidade. As oficinas beneficiam várias pessoas, as quais são ministradas de forma lúdica. Os projetos possibilitam a compreensão melhor das questões trabalhadas pelo GeoPark Araripe, gerando desta forma um processo educativo a partir de práticas ligadas diretamente à Educação Ambiental que norteia o processo formativo dos CIEA e compõem o programa de E.A do GeoPark Araripe contribuindo valorosamente para o ensino, como por exemplo a Geografia.

\section{Considerações Finais}

Deste modo esse trabalho visa mostrar a importância desse elo entre Educação Ambiental e o ensino de Geografia, fazendo essa ligação entre as ações desenvolvidas pelo setor de Educação Ambiental e o ensino, as atividades desenvolvidas pelo setor de "Educação Ambiental" do GeoPark Araripe possuem uma ampla visibilidade em relação as outras atividades realizadas pelos outros setores, as ações são pensadas e projetadas para a educação em si, cabe ao professor de geografia utilizar em suas aulas, dependendo do contexto da aula, usar de maneira adequada e proveitosa.

O desafio que se coloca é de formular uma Educação Ambiental que seja crítica e inovadora em dois níveis: formal e não formal. Assim, ela deve ser acima de tudo um ato político voltado para a transformação social. O seu objetivo principal deve buscar uma perspectiva de ação holística que relaciona sociedade, natureza e o universo, tendo como referência que os recursos naturais se esgotam e que o principal responsável pela sua degradação é o ser humano. O educador (professor) tem a função de mediador na construção de referenciais ambientais e deve saber usá-los como instrumentos para o desenvolvimento de uma prática social centrada no conceito da natureza do meio ambiente como um todo.

O educador pode trabalhar a Educação Ambiental com os alunos, trazendo para um contexto mais local, incluindo os geossitios nas aulas de Geografia Física, Estudos Regionais, de como a questão imobiliária que desmata áreas onde existe uma rica geodiversidade, biodiversidade para realização de grandes construções, o que afeta um determinado ambiente e a vida das pessoas, falando da importância de um Geoparque em determinada localidade até para que esses alunos tenha um sentimento de pertença com o lugar, trabalhar oficinas na sala de aula trabalhando assim a educação lúdica, além da elaboração de uma cartilha que contemple as temáticas físicos-naturais para se trabalhar a geografia escolar por meio da Educação Ambiental, visando assim trabalhos futuros, publicações de artigos que abordem o trabalho desenvolvido.

\section{Agradecimentos}

Agradecemos à Universidade Regional do Cariri (URCA)

\section{Referências}

Albuquerque, F. N. B. de. (2019) Geodiversidade e ensino de Geografia - um ensaio metodológico. Revista Equador (UFPI), 8(2), 170 -185.

Brasil. Ministério do Turismo. Ecoturismo: orientações básicas. (2a ed.), 2010.Lei Federal no 9.795, de 27 de abril de 1999 . Dispõe sobre a educação ambiental, instituia Política Nacional de Educação Ambiental e dá outras providências. Brasília, 1999.

Catalão, V. M. L. (2011) A redescoberta do pertencimento à natureza por uma cultura da Corporeidade. Terceiro incluído. NUPEAT-IESA-UFG, 1(2), 74 81.

Farina, B. C., \& Guadagnin, F. (2007) Atividades práticas como elementos de motivação para a aprendizagem em geografia ou aprendendo na prática. IN: Geografia: Práticas Pedagógicas para o Ensino Médio. (Org.) Rego, N, Castrigiovanni, A. C. e Kaercher, N. A. Artmed.

Friede, R. R.et al. Coleta seletiva e Educação Ambiental: reciclar valores e reduzir o lixo. Educação e Formação, 4(11), 117-141.

Galvão, M. N. C. (2007). Educação ambiental nos assentamentos rurais do MST. Editora Universitária UFPB. 
Research, Society and Development, v. 11, n. 1, e55711124720, 2022

(CC BY 4.0) | ISSN 2525-3409 | DOI: http://dx.doi.org/10.33448/rsd-v11i1.24720

Governo Do Estado Do Ceará. GeoPark Araripe: Histórias da Terra, do Meio Ambiente e da Cultura. Secretaria das Cidades/Projeto Cidades do Ceará Cariri Central. Crato-CE, 2012. 168 p.

Klein, F. M., Escandolhero, J. P. O., Lucchese, N. R., Mercante, M. A.,Fávero, S., Rodrigues, S. C. (2011). Educação ambiental e o ecoturismo na Serra da Bodoquena em Mato Grosso do Sul. Revista Sociedade \& Natureza, 23(2), 311-321,

Lopes, T. S., Abílio, F. J. P. Educação Ambiental Crítica: (re) pensar a formação inicial de professores/as. Revista Brasileira de Educação Ambiental (RevBEA), 16(3), 38-58, 2021.

Loureiro, C. F. B. Educação Ambiental Transformadora. In: Layrargues, P. P. (coord.). Identidades da Educação Ambiental Brasileira. -Brasília: Ministério do Meio Ambiente, 2004, 65-84.

Ludke, M. \& André, M. E. D. A. (2013). Pesquisa em educação: abordagens qualitativas. (2a ed.). E.P.U.

Macedo, L. R. (2012) Políticas Públicas de Esporte e Lazer na Zona Urbana da Cidade de Barbalha/CE. 2012 p.74. (Monografia-Licenciado em Educação Física). Universidade Regional do Cariri, Crato, CE, Brasil.

Macedo, L. R. de. A Contribuição Educacional do Centro de Interpretação e Educação ambiental do Geopark Araripe no Cariri Cearense. XII Congresso Nacional do Meio Ambiente de Poço de Caldas 20 a 22 de maio de 2015. Minas Gerais.

Reis, L. C. L., Semêdo, L. T. A. S., Gomes, R. C. (2012) Conscientização Ambiental: Da Educação Formal a Não Formal. Revista Fluminense de Extensão Universitária, 2(1).

Ressel, L. B., Beck, C. L.C, Gualda, D. M. R., Hoffmann, I. C., Silva, R. M. S., Sehnem, G. D. (2008). O uso do grupo focal em pesquisa qualitativa. The use of the focus group in qualitative. Researchingel uso del grupo focal en la investigación cualitativ. Texto \& contexto Enfermagem, 17(4), 779-786

Santos, J. A., Toschi, M. S. (2015) Vertentes da educação ambiental: da conservacionista à crítica. Fronteiras: Journal of Social, Technological and Environmental Science, 4(2), 241-250.

Silva, F. D. \& Sorrentino, M. Considerações sobre Centros de Educação Ambiental no Brasil: Iniciando uma longa e urgente discussão. Piracicaba-SP,2012. http://www.manuelzao.ufmg.br/assets/files/Biblioteca_Virtual/Consideracoes\%20sobre\%20Centros\%20de\%20Educacao\%20Ambiental\%20no\%20Brasil_ini ciando\%20uma\%20longa\%20e\%20urgente\%20discussao.pdf 